\title{
And Then There Was COVID-19: Do the Benefits of Cooperative Learning Disappear When Switching to Online Education?
}

\author{
Eva Blondeel *(D), Patricia Everaert (D) and Evelien Opdecam
}

\author{
Department of Accountancy, Corporate Finance and Taxation, Ghent University, Sint-Pietersplein 7, \\ 9000 Ghent, Belgium; patricia.everaert@ugent.be (P.E.); evelien.opdecam@ugent.be (E.O.) \\ * Correspondence: eva.blondeel@ugent.be; Tel.: +32-9-264-35-47
}

check for

updates

Citation: Blondeel, E.; Everaert, P.; Opdecam, E. And Then There Was COVID-19: Do the Benefits of Cooperative Learning Disappear When Switching to Online Education? Sustainability 2021, 13, 12168. https://doi.org/10.3390/ su132112168

Academic Editors: Michele Biasutti and Osman Titrek

Received: 13 October 2021

Accepted: 1 November 2021

Published: 4 November 2021

Publisher's Note: MDPI stays neutral with regard to jurisdictional claims in published maps and institutional affiliations.

Copyright: (c) 2021 by the authors. Licensee MDPI, Basel, Switzerland. This article is an open access article distributed under the terms and conditions of the Creative Commons Attribution (CC BY) license (https:/ / creativecommons.org/licenses/by/ $4.0 /)$.

\begin{abstract}
In the spring of 2020, the COVID-19 pandemic induced a rapid shift to online education. University instructors promptly reinvented their teaching methods and developed digital lessons. Cooperative learning has been demonstrated to surpass lecture-based learning (LBL) regarding students' learning processes; therefore, the question arises as to whether the perks of cooperative learning still hold when switching to online education. This study examines whether the benefits of team-based learning (TBL) regarding good teaching (i.e., perceived teaching quality), satisfaction, and performance persist when switching from face-to-face to online education. A quasi-experiment in an undergraduate advanced accounting course compared a non-COVID-19-affected semester to a COVID-19-affected semester. In both semesters, students could choose between a TBL and a LBL path for tutorial sessions. Quantitative survey data $(\mathrm{N}=455)$ indicate TBL outperforms LBL, even when switching to online tools. Good teaching was perceived as even better in the COVID-19-affected semester, and even more so by students in the team-based setting, compared to the lecture-based setting. Students' course satisfaction and performance were unaffected by the switch to online education. This paper shows that TBL still benefits students, even in a blended environment.
\end{abstract}

Keywords: COVID-19; good teaching; satisfaction; performance; team learning; cooperative learning

\section{Introduction \\ 1.1. Impact of COVID-19 on Cooperative Learning}

The 2019 coronavirus pandemic (COVID-19) turned the world of higher education upside down. From one day to the next, students were no longer allowed at the university, leading to a radical shift from on-campus, face-to-face $(\mathrm{F} 2 \mathrm{~F})$ education to online education. This disruptive change thus impacted students' educational experiences [1], as higher education institutions serve an important role in students' academic, personal, and social growth [2]. In addition, there was a substantial reduction in informal contacts with peers and instructors [3]. Apart from the social consequences, the switch from F2F to online education also had consequences for the way course material is taught. The teaching approach in giving an online class often differs from that for a F2F class in terms of skills. More specifically, an online instructor needs other skills compared to a F2F instructor in order to manage the online class setting and to communicate with students in a virtual way [2]. The changing teaching approach possibly has an influence on how students experience the lessons [2]. This is particularly relevant to the tutorial sessions of a technical course such as accounting, which is the setting of the current study, where skills should be practiced by applying accounting principles in exercises. Therefore, the question can be raised as to whether online tutorial courses, to which the world switched in March 2020, are an equivalent alternative to F2F tutorial courses. In other words, the first research question of this study examines if a F2F tutorial can be replaced by an online substitute.

In recent years, the focus in higher education has shifted toward more active learning methods, both in educational practice and in academic research [4]. Active learning incorporates any teaching method that actively involves students in the learning process [5]. 
One way to support active student engagement is through cooperative learning. Cooperative learning implies students working in smaller groups where they help each other in processing and understanding the course material $[5,6]$. Previous research in higher education has distinguished several types of cooperative learning, including team-based learning, in which stable teams work together throughout the whole course. Generally, team-based learning (TBL) — as opposed to traditional lecture-based learning (LBL), which is a rather passive learning style where the instructor is the primary source of informationhas several benefits for higher education students [7]. Some of these benefits are increased performance [8], increased satisfaction [8,9], and increased perceived good teaching [10]. With the switch to online education induced by the COVID-19 pandemic, some instructors set up an online alternative where students were still able to interact with an instructor and cooperate with peer students, which is key to creating an interactive online or blended environment [11]. Despite the endeavors of instructors to implement cooperative learning in an online setting, studies reported that $86.1 \%$ of the students preferred in-person classes [12]. Similarly, Siqueira and Simion [13] found that students perceived active learning in an online environment as less cooperative. Therefore, it could be hypothesized that the positive aspects of cooperative learning - and TBL in particular-were not expected during the COVID-19 pandemic, when a radical switch from F2F to online education was made. According to Goñi et al. [14], cooperation with peers in an online setting could be perceived differently than in a F2F setting. Therefore, the second research question of this study investigates whether the advantages of a TBL approach, regarding good teaching, satisfaction, and performance still hold in an online setting.

To address the two research questions, a quasi-experiment was set up for an undergraduate accounting course in which students could choose between a LBL and a TBL path for tutorial classes. Once students decided on their preferred learning path, which was before the COVID-19 outbreak, the same learning path had to be followed during the entire semester. Allowing students to choose their preferred learning path themselves is based on the philosophy of student-centered education, which states that educational choices should be the student's responsibility [15]. In the middle of the ongoing semester, on 13 March 2020, an immediate switch from F2F to online learning was required due to the COVID-19 virus. To minimize the impact on students, both the LBL and TBL approaches were offered in a format very similar to those that would have been offered on campus. Students who followed the TBL approach worked together in small groups using online breakout rooms. The LBL students followed a tutorial class online (synchronously) where the instructor explained the exercises, as in the F2F format. The present study compares a semester prior to the COVID-19 pandemic with a semester during which the pandemic occurred.

In sum, the aim of this study is to examine whether the switch from a non-COVID-19affected semester to a COVID-19-affected semester had an impact on students' measure of good teaching, satisfaction and performance, and whether these potential differences vary according to the learning path (LBL or TBL). By investigating this effect, the study answers a call to examine the effects of the pandemic on students' performance and satisfaction in practical classes [16]. Additionally, more research has been recommended on students' satisfaction regarding online and blended learning methods [17]. There has also been a scholarly suggestion for more research on different pedagogies applied in online teaching during the COVID-19 pandemic [1], since the empirical evidence is still ambiguous. This paper answers these recent calls.

\subsection{Literature and Hypotheses}

As mentioned, active learning is a cornerstone of higher education today. In addition, literature widely agrees on the positive aspects of TBL, as supporting interaction between students and instructors in every possible learning setting is important [18]. Opdecam and Everaert [19] found that TBL students perceive good teaching to be higher than LBL students did. Good teaching is defined as students' perception of the teaching quality of 
an instructor, in terms of making the subject interesting, understanding difficulties of the students, helping the students, explaining the content in a good way, providing helpful feedback, and motivating students [20]. The difference in good teaching between both learning paths is mainly driven by the instructor explaining the exercises [19]. Since the students in the TBL setting took part in the tutorial classes in smaller groups, a more personal instruction style was adopted, which the students appreciated. The instructor tried to understand the difficulties students had with the material and explained these topics within the small teams. Moreover, this way of teaching provided more helpful (individual) feedback and helped in motivating the students to do their best [21]. In the beginning of 2020, as the COVID-19 pandemic spread, university students experienced fundamental changes in their academic learning processes due to obligatory school closures [3]. A disruptive shift from F2F to online learning was inevitable and it severely affected students' educational experience [1]. The immediate switch to an online setting due to the COVID-19 pandemic led to a lack of physical presence on campus and, consequently, a substantial reduction of informal contacts with peers and instructors [3]. Due to this lack of personal and physical contact with the instructor, less opportunities for personal feedback or individual explanations were possible, leading to expected lower ratings on the good teaching scale during the COVID-19 period. Since the TBL sessions had to be held online, in a less supporting environment, the current study expects the positive difference in good teaching between the TBL and LBL conditions to be smaller in the COVID-19 period, leading to the following three sub-hypotheses.

Hypotheses 1 (H1a): Students under TBL conditions rated their experience as higher on the good teaching scale compared to students under LBL conditions in both the non-COVID19-affected and COVID-19-affected semesters.

Hypotheses 1 (H1b): In the COVID-19-affected semester, students rated their experience as lower on the good teaching scale compared to the non-COVID-19-affected semester.

Hypotheses 1 (H1c): The difference in good teaching between the TBL and LBL conditions is smaller in the COVID-19-affected semester compared to the non-COVID-19-affected semester.

Healy et al. [8] and Opdecam and Everaert [19] also found TBL to have a positive influence on students' satisfaction with the course and the tutorials. According to Healy et al. [8], students especially appreciate the social interaction in a TBL setting, both with the instructor and with peer students. Due to these small group discussions and interactions, students perceive that they develop more skills and knowledge, which in turn positively affects their satisfaction [22]. The ability to work in smaller groups and to have greater interaction with peers gave students pleasure and a sense of fulfillment during the learning process. Since the TBL approach is more personal and implies close interaction with peers, students might experience greater pleasure in this type of learning path, leading, in turn, to higher satisfaction. However, with the outbreak of COVID-19 and accompanying restrictions, physical contact between students and instructors was no longer possible. Therefore, students' satisfaction is expected to have decreased in times of COVID-19, due to the absence of F2F education and contact. Ghaderizefreh and Hoover [23] emphasized the importance of human social interaction, also in an online learning environment. Staying in touch with peers during the COVID-19 pandemic is of utmost importance [3], and TBL has the potential to fulfill this need for connectedness [21]. However, students were not able to physically sit around a table with each other, comparing the different solutions of the exercises the team members might have had, so whether peer learning satisfies students as much as a F2F learning context is in question. Therefore, it is hypothesized that the positive effect on satisfaction experienced with TBL will diminish when switching to a fully online setting due to COVID-19, as follows. 
Hypotheses 2 (H2a): Students under TBL conditions report higher satisfaction compared to students under LBL conditions in both the non-COVID-19-affected and COVID-19-affected semesters.

Hypotheses 2 (H2b): In the COVID-19-affected semester, students report lower satisfaction compared to students in the non-COVID-19-affected semester.

Hypotheses 2 (H2c): The difference in student satisfaction between the TBL and LBL conditions is smaller in the COVID-19-affected semester compared to the non-COVID-19affected semester.

The literature on TBL and cooperative learning in general widely agrees on the positive effects of cooperative learning on student performance (e.g., $[9,24,25])$. Multiple studies have also examined the effect of the COVID-19 pandemic on academic performance, but they have led to ambiguous results. Pokhrel and Chhetri [1] concluded that students' performance is likely to decline due to the distance learning setting. This negative performance effect is due to reduced contact hours for students and the lack of personal contact with the teacher when facing difficulties in their learning experience [1]. Gopal et al. [14], on the other hand, conclude the opposite: students perform better in online learning, compared to traditional F2F learning. Their study mentioned that the positive performance effect is due to instructors who teach more efficiently in an online setting [16]. In the present study, the negative effects of the pandemic are expected to outweigh the previously established positive effects on students' learning processes, since students experienced tremendous changes in their life and learning processes. This is why the COVID-19 pandemic is expected to have a negative performance effect. In addition, the positive performance effect of TBL compared to LBL is expected to decline when switching to a fully online environment, since it was, for example, harder for the instructor to monitor whether students worked together in the breakout rooms on the exercises. This led to the following sub-hypotheses.

Hypotheses 3 (H3a): Students under the TBL conditions report higher performance compared to students under the LBL conditions, in both the non-COVID-19-affected and COVID-19-affected semesters.

Hypotheses 3 (H3b): The performance of students in the COVID-19-affected semester was lower on the final exam compared to students in the non-COVID-19-affected semester.

Hypotheses 3 (H3c): The difference in performance between the TBL and LBL conditions is smaller in the COVID-19-affected semester compared to the non-COVID-19-affected semester.

In summary, the tested relations propose that an active learning approach, in the form of TBL, outperforms a traditional lecture-based approach, replicating the findings of Opdecam and Everaert [19], Strand Norman et al. [9], Healy et al. [8], and Johnson et al. [24]. In addition, the COVID-19 pandemic is expected to have a detrimental effect on students learning processes. Last, TBL is also expected to be harder to organize online compared to on campus, which leads to a decrease in its positive effects. A graphical representation of these expected effects is presented in the Appendix A.

\section{Materials and Methods}

\subsection{Setting}

This study was set up for first-year undergraduate students at a large research-oriented university in Belgium. The transition to higher education in Belgium does not require any formal selection or entrance criteria (except for medicine, dentistry, and arts education), which is comparable to most other countries in Central Europe. This open admission system results in a high degree of heterogeneity among incoming students in terms of prior knowledge, attitudes, and skills [26]. Due to this, a substantial portion (25\%) of the incoming students must redo their first undergraduate year. These students are excluded from this study. Only students entering the program for the first time were included in this 
study, so-called generation students. Accordingly, the study participants are 18 years old. No international students were included.

The study relates to the tutorial classes of a first-year undergraduate advanced financial accounting course for business economics students. In the first year, undergraduate business economics students take two accounting courses. The first introductory accounting course is in the first (fall) semester of the academic year. The advanced follow-up accounting course is in the second (spring) semester of this first year. Both semesters comprise 12 weeks of classes, with a weekly lecture $(3 \mathrm{~h})$ and weekly tutorial session $(1.5 \mathrm{~h})$, and a summative exam at the end of the semester. The tutorials include practical exercises covering applications of accounting principles taught during the lectures. In the first semester, all tutorial classes take place in a large auditorium, where the instructor explains the exercises. For the practical sessions of the second semester, students can choose between two different learning paths: LBL and TBL. Since both learning paths differ substantially from each other, an orientation session is organized at the start of the semester, providing practical information on both the TBL and LBL paths. In addition, the students are introduced to the concept of TBL. One week following the orientation session, students are required to enroll in one of the two learning paths. During the whole semester, students attend either the TBL or the LBL tutorials.

In the LBL path, the instructor presents the complete solution of the exercises; these tutorials classes are lecture-based and take place with a large group of 150-200 students. This type of learning path is rather passive and is comparable to that used for the tutorial classes of the first semester. The TBL path, on the contrary, is a form of active learning and is designed according to the five elements of cooperative learning, as described by Johnson and Johnson [27]: positive interdependence, individual accountability, promotive F2F interaction, social and interpersonal skills, and group processing. Students in the TBL path attend classes in a much smaller group of 36 students and work during class in small teams of 5 to 6 persons, which are stable throughout the whole semester. The aim of TBL is for students to compare preparation among team members, discuss differences and potential problems, and work together to find a solution to the exercises. Every student must prepare the exercises individually, at home, before class. Only if all members of the team have prepared the exercises can a real discussion take place. After each tutorial session, the teams are required to complete a team report on their cooperative processes and learning results. Hence, this type of learning path is more active and cooperative, with the students themselves being the main source of instruction.

However, when COVID-19 made its appearance, both learning paths had to be organized in an online version. To make the transition to online learning as smooth as possible for all students, the same two learning paths were offered concurrently in an online setting, without changing the structure of either the LBL or the TBL approach. The LBL path was organized in a large Zoom session, where the instructor explained the exercises. Breakout rooms were used for the TBL path, where each team could cooperate in a separate breakout room. The instructor went from one breakout room to the next, to answer students' questions. Students also had the ability to raise their hand, so that the instructor would know which team had a question and needed help. All of the course material and course content were identical in both learning paths and under both learning conditions.

\subsection{Research Design and Procedure}

The study was conducted during the second semester of the academic year 2018-2019 and the second semester of the subsequent academic year (2019-2020). Both semesters run from February until May. In March 2020, the COVID-19 pandemic struck in Belgium, resulting in a switch from $\mathrm{F} 2 \mathrm{~F}$ classes to an online alternative in the middle of the second semester (week 6). Hence, the first year included in this study (2018-2019) was a regular semester, with all classes being F2F, which this study calls the non-COVID-19-affected semester. The second year (2019-2020) involved a switch from F2F to online education in the middle of the semester, which this study calls the COVID-19-affected semester. 
The aim of the study is twofold: (1) to investigate the effect of the COVID-19 pandemic on students' learning outcomes and (2) to examine if this effect is different with regard to the separate learning paths. Therefore, the study is designed as a quasi-experiment with a $2 \times 2$ factorial design. For the first factor, represented by the variable year, a semester without COVID-19 (year $=1$ ) is compared to a semester in which COVID-19 made its appearance in the middle of the ongoing semester (year $=2$ ). The second factor, learning path, denotes the students' choice to follow tutorial classes under either the LBL approach (learning path $=1$ ) or the TBL approach (learning path $=2$ ). A full experiment where students are randomly assigned to one of the two learning paths was not possible, since, for ethical reasons, the university will not permit students to be randomly allocated to one of the two learning paths.

In both semesters under study, two surveys were conducted. The first questionnaire was administered at the start of the second semester (week 2). This survey asked students by the start of the semester to report which learning path they had chosen: TBL or LBL. Students stayed in the chosen learning path during the entire semester. This information was also double-checked by the administration, to make sure that the indicated learning path matched the students' actual enrollment. Students also entered their student ID code and registered their gender. At the end of the semester (week 12), before the final summative exam, a second questionnaire was given to evaluate the students' learning paths. The surveys were conducted during official class time. A paper-based questionnaire was given to all students, and the instructor was present when the instrument was administered. However, due to COVID-19 restrictions, the second questionnaire during the COVID-19affected semester was administered with an online survey tool, asking the same questions. The students were ensured about the confidentiality of their answers when filling out the questionnaire and completed an informed consent form before participating. An overview of the course structure and semester timeline is shown in Figure 1.

Non-COVID-19-affected semester (2018-2019, year $=1)$
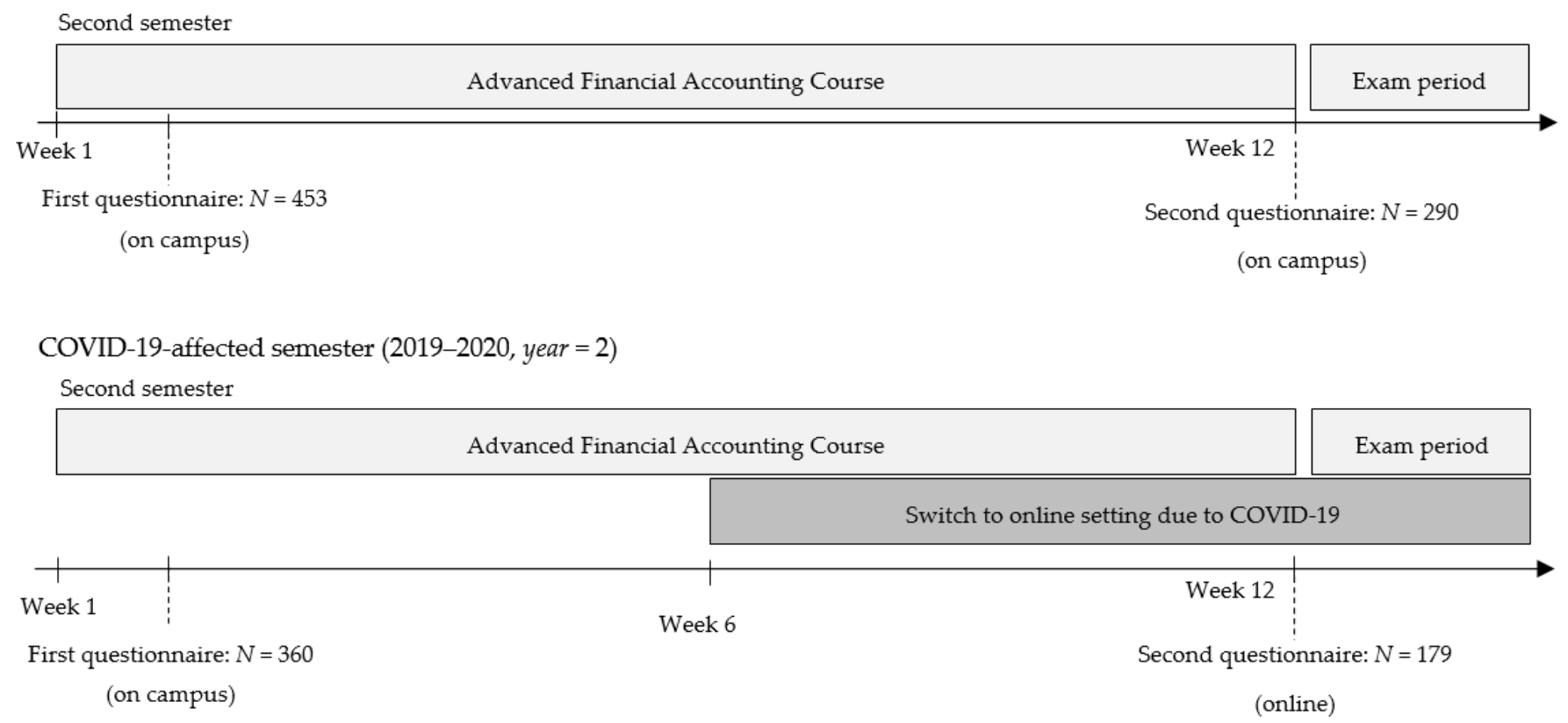

Figure 1. Research design, course structure, and timeline of the data collection.

\subsection{Participants}

In the first year of this study (2018-2019), 691 students were enrolled in the advanced financial accounting course. However, only 580 students were generation (i.e., first-time) students. Consequently, the other 111 students were excluded from the sample. For the second year of the study (2019-2020), 604 students were enrolled, 506 of whom took 
the course for the first time. Since attendance is not mandatory for the course, not all students were present in both lectures when the first and second questionnaires were given, leading to a smaller sample size. During the first year, 453 students filled out the first questionnaire (a 78\% response rate) and 290 students also filled out the second questionnaire (a 50\% response rate). In the second year, 360 students participated in the questionnaire at the start of the semester (a 71\% response rate) and 179 of them also completed the second questionnaire (a 35\% response rate). Depending on which variable is used in the analyses, the sample sizes will vary.

\subsection{Instruments}

The second questionnaire, administered during the last lecture of the course, is the most important instrument in this study, since it evaluates the success of TBL and LBL. First, good teaching is measured as in the Course Experience Questionnaire (CEQ). The CEQ is an existing scale, developed by Ramsden [20] and has been successfully used before in an accounting course [28], which is also the setting of the current study. In addition, the CEQ is specifically designed for measuring teaching quality in higher education within a specific course [20]. The CEQ consists of five different elements (good teaching, clear goals, appropriate workload, generic skills, and appropriate assessment) [20]. For the context of this study, only the first element, i.e., good teaching, is of interest and consists of six items that request information on how students perceive the instructors' teaching quality. It measures students' perceptions on the clarity of the explanation by the teacher, the effort and time the staff put into explaining difficulties, the enthusiasm of the teacher to make the subjects interesting, and the feedback the instructor gives on problems students might have. The same steps to operationalize these items are used as described by Opdecam and Everaert [19]. The items are rated on a five-point Likert scale, ranging from one, "completely disagree," to five, "completely agree." These items and their Cronbach's alpha values and factor loadings are presented in Table 1. The Cronbach's alpha values are satisfactory, ranging from 0.67 to 0.78 .

Second, the survey asks students whether they liked their chosen learning path and if their learning path met their expectations. To measure course satisfaction, three items from Janvrin [29] were used, but these were adapted slightly, following Opdecam and Everaert [19]. The items are measured on a five-point Likert scale, ranging from one, "completely disagree," to five, "completely agree." The second part of Table 1 presents these items and their Cronbach's alpha values and factor loadings. None of the Cronbach's alpha values could be improved by deleting an item, and the factor loadings are reasonable.

The third dependent variable of this study, performance, is measured as the score the students obtained on the final, summative exam at the end of the advanced financial accounting course. This exam consists of two parts: a theoretical part with multiple-choice questions and a practical part with integrated exercises. These exercises were similar to those in the tutorial sessions. Performance on both parts of the exam was measured out of a total score of 20. To pass the course, students had to obtain a score of at least 10 out of 20. These data were recorded by the course instructors at the end of the semester. The format of the summative exam was the same in both the non-COVID-19-affected and COVID-19-affected semesters. In both years, the exam was organized in a paper-based format. Therefore, the variable performance is comparable over both semesters.

The two control variables included in this study, gender and ability, were obtained from the first questionnaire and the administrative records. The exam grade for the first semester's introductory accounting course is used to measure ability. Prior research indicates that female students often achieve higher grades compared to male students [30]. Previous research also found a strong and positive correlation between exam performance and ability [31]. Therefore, the exam grade for the first semester introductory accounting course is used as the measure for ability. Both variables are included in all the analyses, to control for students' initial accounting performance and gender differences. 
Table 1. Items, Cronbach's alpha values, and factor loadings of good teaching and satisfaction.

\begin{tabular}{|c|c|c|c|}
\hline \multirow{2}{*}{\multicolumn{2}{|c|}{$\begin{array}{c}\text { Items } \\
\text { Good teaching scale (6 items) }\end{array}$}} & \multirow{2}{*}{$\begin{array}{c}\text { Cronbach's Alpha } \\
0.864 \\
\end{array}$} & \multirow[t]{2}{*}{ Factor Loading } \\
\hline & & & \\
\hline 1. & The teaching staff worked hard to make their subjects interesting. & & 0.722 \\
\hline 2. & The staff put a great deal of effort to understand difficulties I might be having with my work. & & 0.766 \\
\hline 3. & The staff put a great deal of time into helping me complete the assignment. & & 0.755 \\
\hline 4. & The instructors were extremely good at explaining things. & & 0.665 \\
\hline 5. & The teaching staff normally gave me helpful feedback on how I was doing. & & 0.780 \\
\hline 6. & The teaching staff of this course motivated me to do my best. & & 0.724 \\
\hline & Satisfaction scale (3 items) & 0.743 & \\
\hline 1. & I learned a great deal during the tutorials (team-based or lecture-based). & & 0.700 \\
\hline 2. & If I could again choose a learning path, I would choose the same one. & & 0.843 \\
\hline 3. & The tutorials met my expectations. & & 0.700 \\
\hline
\end{tabular}

\subsection{Data Analysis}

SPSS Version 27 was used to analyze the data. Cronbach's alpha values were measured to ensure the reliability of the items. In addition, the scale's factor structure, internal consistency, and item correlation were examined. Descriptive statistics, correlations, and analyses of covariance (ANCOVAs) were calculated to test the hypotheses.

\section{Results}

\subsection{Frequencies, Descriptive Statistics, and Group Means}

Panel A of Table 2 presents the frequency statistics: 446 students are enrolled in year 1 (non-COVID-19-affected semester) and 356 students in year 2 (COVID-19-affected semester). In both years, more than half of the students opted for the team-based approach, as opposed to the lecture-based approach (60\% in year 1 and $55 \%$ in year 2). In both years, there were more male than female students $(63 \%$ in year $1,59 \%$ in year 2$)$.

The descriptive statistics are presented in Panel B of Table 2. The mean for the ability variable is 12.15 (scored out of 20), that is, the grade on the introductory accounting course in the previous semester. For the summative exam of the advanced accounting course, students obtained an average score of 11.34 out of 20. Both good teaching and satisfaction are rated relatively high on a five-point Likert scale $(\mathrm{M}=4.21$ and $\mathrm{M}=4.03$, respectively).

When the lecture-based setting is compared with the team-based setting (Panel C of Table 2), a statistical difference is noted for good teaching and satisfaction. Students under the team-based approach gave higher scores for both good teaching and satisfaction compared to students under the lecture-based approach.

When the non-COVID-19-affected semester is compared with the COVID-19-affected semester (Panel D of Table 2), a statistical difference is noted for good teaching $(p<0.001)$. Good teaching is rated significantly higher by students in the COVID-19-affected semester $(\mathrm{M}=4.35)$ compared to students in the non-COVID-19-affected semester $(\mathrm{M}=4.12)$. No differences are found between the semesters in satisfaction and performance. In addition, no significant difference is noted for ability, which means that both years are comparable. As mentioned above, the fall semester was a non-COVID-19-affected semester for all years. Hence, no difference in cohorts is noted.

\subsection{Correlations}

Table 3 shows the correlations between the variables. The variables ability and performance are highly correlated with each other $(r=0.770, p<0.001)$, which is expected, since the score students obtained on the introductory accounting course is a good predictor of the score they will obtain on the final exam of the advanced accounting course. The 
variables good teaching and satisfaction are also highly correlated $(r=0.587, p<0.001)$, which was also found in previous studies [16]. No other significant correlations are noted.

Table 2. Summary statistics.

\begin{tabular}{|c|c|c|c|c|c|c|}
\hline \multicolumn{7}{|c|}{ Panel A: Frequencies for year, learning path, and gender. } \\
\hline & \multirow[b]{2}{*}{ Frequency } & \multirow[b]{2}{*}{$\%$} & \multicolumn{2}{|l|}{ Male } & \multicolumn{2}{|l|}{ Female } \\
\hline & & & Frequency & $\%$ & Frequency & $\%$ \\
\hline \multicolumn{7}{|c|}{ Non-COVID-19-affected semester $($ year $=1$ ) } \\
\hline Lecture-based setting & 180 & $40 \%$ & 118 & $42 \%$ & 62 & $38 \%$ \\
\hline \multirow[t]{2}{*}{ Team-based setting } & 266 & $60 \%$ & 163 & $58 \%$ & 103 & $62 \%$ \\
\hline & 446 & $56 \%$ & 281 & $63 \%$ & 165 & $37 \%$ \\
\hline \multicolumn{7}{|c|}{ COVID-19-affected semester (year $=2$ ) } \\
\hline Lecture-based setting & 161 & $45 \%$ & 106 & $51 \%$ & 55 & $37 \%$ \\
\hline \multirow[t]{2}{*}{ Team-based setting } & 195 & $55 \%$ & 102 & $49 \%$ & 93 & $63 \%$ \\
\hline & 356 & $44 \%$ & 208 & $59 \%$ & 148 & $41 \%$ \\
\hline Total & 802 & $100 \%$ & 489 & & 313 & \\
\hline
\end{tabular}

Panel B: Descriptive statistics for ability, performance, good teaching, and satisfaction.

\begin{tabular}{cccccc}
\hline & N & Minimum & Maximum & Mean & St. dev. \\
\hline ability & 776 & 1.00 & 20.00 & 12.15 & 3.71 \\
good teaching & 468 & 1.83 & 5.00 & 4.21 & 0.59 \\
satisfaction & 469 & 1.00 & 5.00 & 4.03 & 0.79 \\
\hline performance & 753 & 2.00 & 20.00 & 11.34 & 4.75 \\
\hline
\end{tabular}

Panel C: Group means and $t$-tests between LBL and TBL.

LBL

TBL

\begin{tabular}{|c|c|c|c|c|c|c|}
\hline & $\mathbf{N}$ & Mean & $\mathbf{N}$ & Mean & $t$-Value & $p$-Value \\
\hline ability & 322 & 12.43 & 446 & 12.01 & 1.530 & 0.127 \\
\hline good teaching & 174 & 3.93 & 293 & 4.38 & -8.550 & 0.000 \\
\hline satisfaction & 175 & 3.77 & 293 & 4.19 & -5.774 & 0.000 \\
\hline performance & 317 & 11.17 & 430 & 11.51 & -0.949 & 0.343 \\
\hline
\end{tabular}

Panel D: Group means and $t$-tests between the non-COVID-19-affected and the COVID-19-affected semester.

\begin{tabular}{|c|c|c|c|c|c|c|}
\hline & \multicolumn{2}{|c|}{ Non-COVID-19-Affected Semester } & \multicolumn{2}{|c|}{ COVID-19-Affected Semester } & \multirow[b]{2}{*}{$t$-Value } & \multirow[b]{2}{*}{$p$-Value } \\
\hline & $\mathbf{N}$ & Mean & $\mathbf{N}$ & Mean & & \\
\hline ability & 437 & 12.07 & 339 & 12.25 & -0.670 & 0.503 \\
\hline good teaching & 289 & 4.12 & 179 & 4.35 & -4.063 & 0.000 \\
\hline satisfaction & 290 & 4.00 & 179 & 4.07 & -0.931 & 0.352 \\
\hline performance & 416 & 11.27 & 337 & 11.42 & -0.430 & 0.667 \\
\hline
\end{tabular}

Table 3. Correlation table.

\begin{tabular}{|c|c|c|c|c|c|}
\hline & & 1 & 2 & 3 & 4 \\
\hline 1. & ability & 1 & & & \\
\hline 2. & good teaching & $-0.018(0.696)$ & 1 & & \\
\hline 3. & satisfaction & $0.000(0.993)$ & $0.587^{* *}(<0.001)$ & 1 & \\
\hline 4. & performance & $0.770^{* *}(<0.001)$ & $0.021(0.649)$ & $0.074(0.114)$ & 1 \\
\hline
\end{tabular}

The $p$-values are in parentheses and two-tailed. ${ }^{* *}$ Significant at the 0.01 level (two-tailed).

\subsection{Hypothesis Testing}

First, the relation between good teaching and both learning path and year was analyzed (H1). The following was expected: 
(a) students under the TBL conditions would report a higher score of good teaching experience compared to students under the lecture-based conditions (H1a);

(b) students in the COVID-19-affected semester would report a lower score of good teaching experience compared to students in the non-COVID-19-affected semester (H1b);

(c) the difference in good teaching between the team-based and lecture-based conditions would be smaller in the COVID-19-affected semester compared to the non-COVID-19affected semester (H1c).

To test these three sub-hypotheses, the following equation is used:

good teaching $=$ gender + ability + year + learning path + year $*$ learning path $+\varepsilon$

Panel A of Table 4 shows the ANCOVA results of testing Equation (1), where good teaching is the dependent variable. The model is significant $(p<0.001)$, and an acceptable adjusted $R^{2}$ value is noted (0.198). Both covariates gender and ability have no significant influence on good teaching. However, a significant main effect for both year $(p=0.001)$ and learning path $(p<0.001)$ is found. To examine the directions of both main effects, Panel B reports the estimated marginal means for both year and learning path. H1a is supported, since the estimated marginal mean of good teaching for students under the team-based conditions $(\mathrm{M}=4.430)$ is higher compared to the estimated marginal mean under the lecture-based conditions $(\mathrm{M}=3.918)$. Students under the team-based conditions report a higher good teaching experience compared to students under the lecture-based conditions. In addition, students in the COVID-19-affected semester $(M=4.266)$ report significantly higher good teaching compared to students in the non-COVID-19-affected semester $(M=4.082)$, which rejects $\mathrm{H} 1 \mathrm{~b}$. More specifically, this result confirms the opposite of what was hypothesized. Instead of a lower good teaching level due to COVID-19, students rated the good teaching higher in times of COVID-19. Furthermore, a significant interaction effect is found between year and learning path $(p<0.001)$. According to the estimated marginal means reported in Panel B, students in the team-based setting reported higher good teaching in the COVID-19-affected semester compared to the non-COVID-19affected semester. However, a decrease in good teaching is noted for the lecture-based setting, showing a slightly lower good teaching score in the COVID-19-affected semester compared to the non-COVID-19-affected semester. A graphical representation of this interaction effect is presented in Part A of Figure 2. This result rejects H1c. More specifically, the opposite of the expected result is obtained. The difference in good teaching between the team-based and lecture-based conditions is greater for the COVID-19-affected semester compared to the non-COVID-19-affected semester.

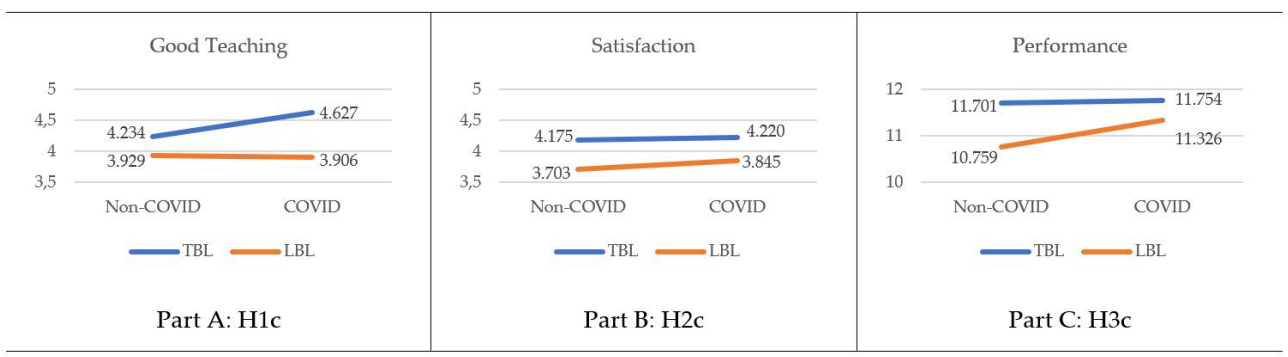

Figure 2. Graphical representations for $\mathrm{H} 1 \mathrm{c}$ to $\mathrm{H} 3 \mathrm{c}$.

Second, students' satisfaction is examined for both years and both learning paths (H2). It is hypothesized that:

(a) students under the TBL conditions will report higher satisfaction compared to students under the lecture-based conditions (H2a);

(b) students in the COVID-19-affected semester will report lower satisfaction compared to students in the non-COVID-19-affected semester (H2b); 
(c) the difference in satisfaction between the team-based and lecture-based conditions will be smaller in the COVID-19-affected semester compared to the non-COVID-19 semester $(\mathrm{H} 2 \mathrm{c})$.

To test these three sub-hypotheses, the following equation is used:

$$
\text { satisfaction }=\text { gender }+ \text { ability }+ \text { year }+ \text { learning path }+ \text { year } * \text { learning path }+\varepsilon
$$

The results in Panel A of Table 5 are significant $(p<0.001)$, and find only a significant main effect for learning path $(p<0.001)$. The estimated marginal means in Panel B show that students in the team-based setting are more satisfied with the tutorial sessions compared to students in the lecture-based setting. The variables gender, ability, and year have no significant influence on satisfaction. In addition, no significant interaction effect is found $(p=0.529)$, as shown in Part A of Table 5. Accordingly, only H2a can be confirmed; students in the TBL condition were more satisfied compared to students in the lecture-based setting. Neither H2b nor H2c can be confirmed. The COVID-19 pandemic had no influence on students' satisfaction for the tutorial classes in this course.

Table 4. Test of H1.

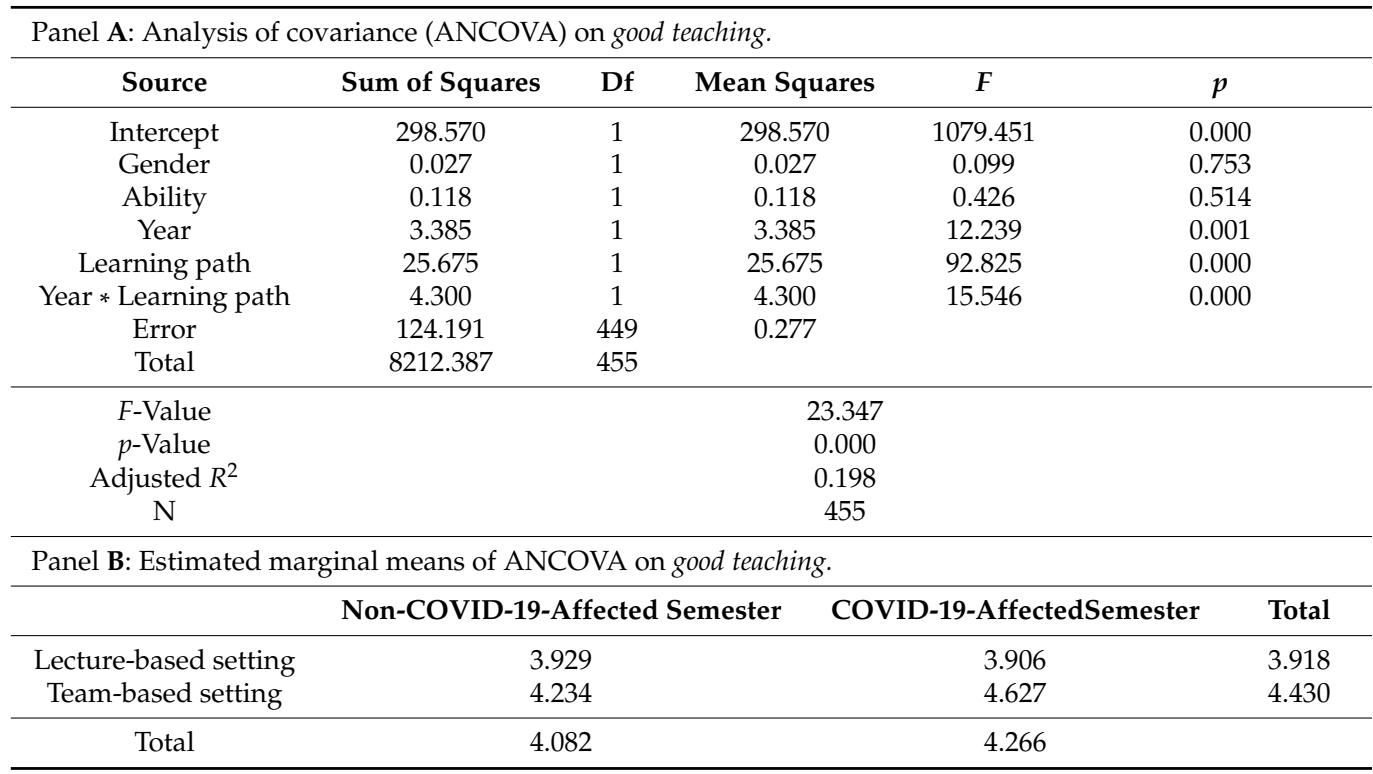

Third, this study examined whether student performance differs between both years and both learning paths. Hypothesis 3 predicts the following:

(a) the performance of students under the TBL conditions will be higher compared to that of students under the lecture-based conditions ( $\mathrm{H} 3 \mathrm{a})$;

(b) the performance of students in the COVID-19-affected semester will be lower than that of students in the non-COVID-19-affected semester (H3b);

(c) the difference in performance between the team-based and lecture-based conditions will be smaller in the COVID-19-affected semester compared to the non-COVID-19-affected semester $(\mathrm{H} 3 \mathrm{c})$.

To test these three sub-hypotheses, the following equation is used:

$$
\text { performance }=\text { gender }+ \text { ability }+ \text { year }+ \text { learning path }+ \text { year } * \text { learning path }+\varepsilon
$$

The results in Panel A of Table 6 show no significant effect of gender, ability, or year on performance and no interaction effect. However, learning path has a significant influence on performance $(p=0.003)$. Panel B shows that the estimated marginal mean of student performance in the team-based setting is significantly higher compared to student performance under the lecture-based conditions. Therefore, H3a is supported. No evidence is 
found for $\mathrm{H} 3 \mathrm{~b}$ or $\mathrm{H} 3 \mathrm{c}$, as also shown in Figure 2. The results of all three hypotheses remain the same when excluding the interaction-term from the analyses.

Table 5. Test of $\mathrm{H} 2$.

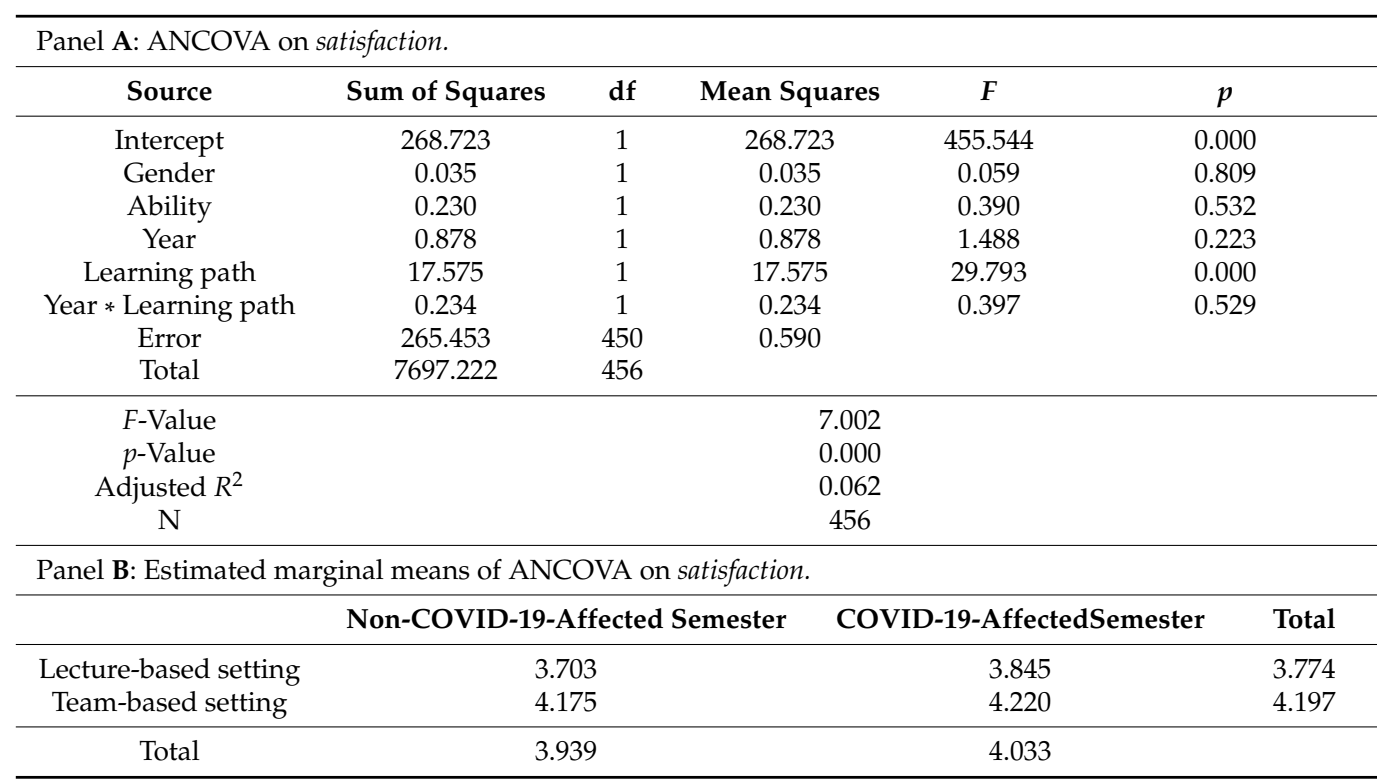

Table 6. Test of H3.

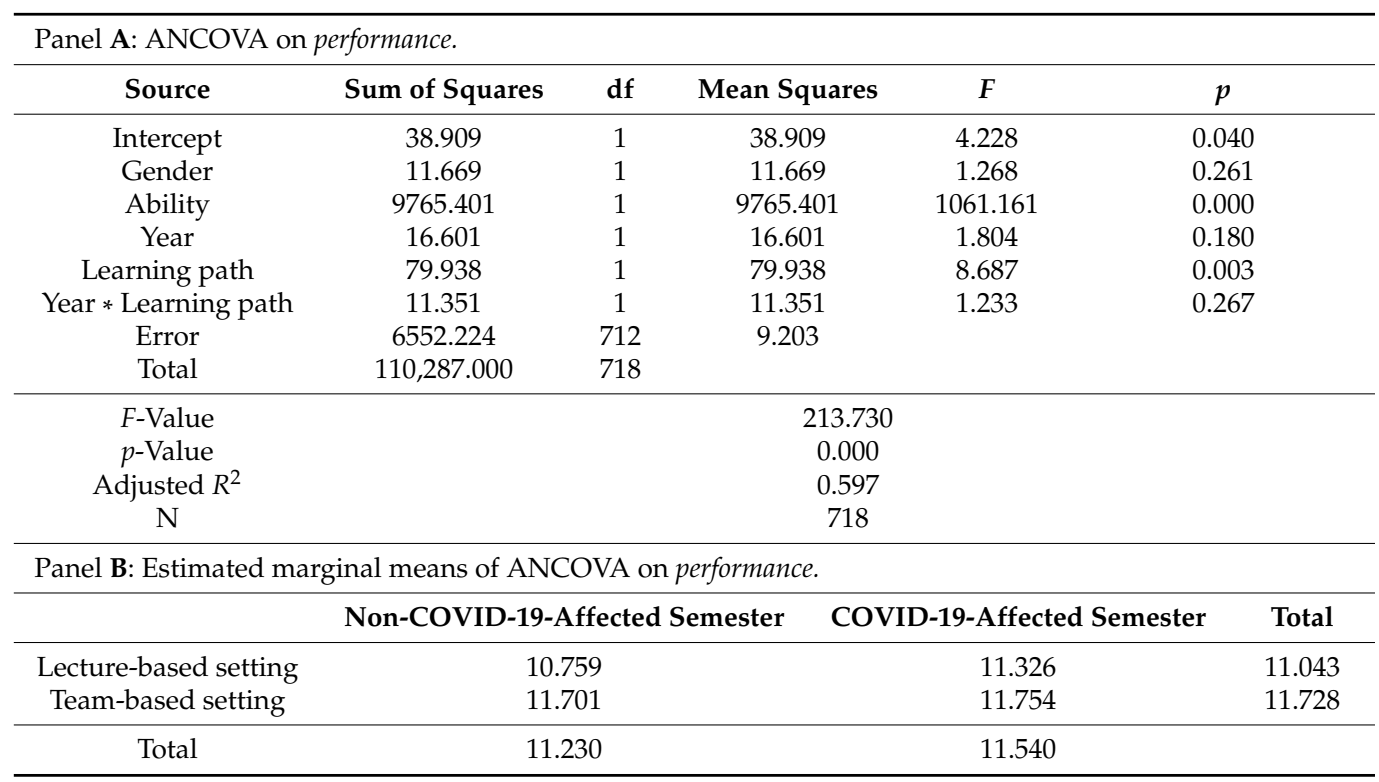

\section{Discussion}

The COVID-19 pandemic has undeniably completely transformed the educational landscape. As of early 2020, an entire switch from F2F to online education had to be made, which no instructor or student ever anticipated. Therefore, the current study attempts to determine whether it is possible to effectively organize TBL-which was always hosted in a F2F context before the outbreak of the COVID-19 virus-in an online setting. More specifically, a non-COVID-19-affected semester is compared to a COVID-19-affected semester. In both semesters, students chose between a TBL or a LBL approach for their tutorials. Quantitative survey data were collected to examine the students' experiences regarding the learning paths they chose. Consequently, the differences between the learning paths in both a F2F and an online setting can be explored.

Surprisingly, the data revealed that students rated the good teaching higher in the COVID-19-affected semester than in the non-COVID-19-affected semester, regardless of 
their learning path. This result is the opposite of what was expected on the basis of $\mathrm{H} 1 \mathrm{~b}$, which predicted a lower good teaching score in the COVID-19-affected semester. However, this conclusion is actually positive; since students rated good teaching higher in COVID-19 times, they appear to have greatly appreciated the way the instructors tried to teach the material and tried to support the students to the best of their abilities in an online environment. A high good teaching rating is also found to be the principal determinant of a good online learning setting [32]; therefore, the results of this study can be concluded as positive. When the switch to a fully online setting had to be made, the instructors of both learning paths tried to set up an equally valuable alternative for the F2F classes, to make the transition to online learning as smooth as possible. Despite the rapid switch, sufficient structure was offered to all students, since both learning paths were still offered synchronously, and in the same manner as they were offered F2F. In addition, students still had the opportunity to ask questions. The differences with the F2F versions were thus minimized, for which the students appreciated the instructors' efforts. Consequently, no structural changes were perceived by the students, leading to a smooth transition from in-class to online education [33]. Scull et al. [34] also indicated that many instructors put in a great deal of effort to support all students in this transition to online education, which the students also appreciated. Hence, this study establishes that an online alternative as similar as possible to the F2F version was highly appreciated and perceived positively by the students. This statement is in line with the conclusions of Gopal et al. [16] and the equivalency theory of digital learning, which states that distance learners and F2F learners can experience similar educational outcomes when similar learning experiences are offered.

An even more surprisingly and hopeful finding is that, for both learning paths, satisfaction and performance remained stable during the COVID-19-affected semester compared to the non-COVID-19-affected semester. A similar conclusion was drawn by Loton et al. [35]: the rapid introduction of a fully online learning environment did not lead to a substantial decrease in student satisfaction. Despite the fact that students were not able to sit next to their peers in an auditorium and discuss the exercises in person, satisfaction with the tutorials did not decrease. According to Gopal et al. [16], instructor quality-and thus students' perception of good teaching-is the major determinant of students' satisfaction with an online course. Consequently, it can be concluded that the increase in good teaching in the current study avoided a decrease in course satisfaction. In addition, Holzer et al. [3] underlined the importance of addressing learners' needs in an online environment. Since both the LBL and TBL were offered the same way online as the students chose in the F2F context, all students' needs were met, leading to a steady level of satisfaction. With regard to performance, Kronenfeld et al. [36] and El Said [37] also detected no differences in learning outcomes between in-person and online education. In addition, research has shown that the effect on performance depends mostly on how the course is designed [16]. According to the results of the current study, students appreciated the current online course design, and no differences in performance were noticed between both semesters.

The current study has also revealed that students in a TBL context (1) rate good teaching higher, (2) have a higher level of course satisfaction, and (3) obtain higher scores on the final summative exam, compared with students participating in a LBL context. This result replicates prior research, since it is in line with the conclusions of Healy et al. [8], Andres [25], and Strand Norman [9]. The assertion that TBL outperforms LBL is therefore a robust finding, since the same results are found within the sample and in the research context of the current study. It can be stated that the positive effects of the five elements of cooperative learning [27], the mandatory preparation of the exercises, the completion of the team report, and so forth, also hold in an online context, even after an immediate switch from F2F to online learning. The more personal teaching approach applied by the instructors in the TBL setting compared to the LBL setting is highly appreciated by the TBL students, which also leads to greater satisfaction [22]. Moreover, in the TBL setting, students committed themselves to weekly preparation of the exercises before coming to the 
tutorial class. The greater effort TBL students put into their learning process beneficially influences their performance at the end of the semester [24].

Another finding indicates that the overall increase in good teaching between the nonCOVID-19-affected and the COVID-19-affected semester varies with the chosen learning path. Hypothesis 1c predicted that the positive difference in good teaching for the TBL setting compared to the LBL setting would decrease when the forced switch to online education was made. Nevertheless, the opposite seems to be true: students in the TBL setting rated the teaching quality even higher in the COVID-19-affected semester than the students in the non-COVID-19-affected semester did. This result is in line with the work of Jackson et al. [21], who concluded that students overall rated online TBL positively. However, the opposite can be concluded for the LBL students, since good teaching decreased from the non-COVID-19-affected semester to the COVID-19-affected semester for the students following the tutorial classes in the more passive learning path. The strength of TBL lies in the more personal interactions with peers and instructors. In a F2F context, students in the TBL setting participated in the tutorial classes in small groups, resulting in less distance between the instructor and the students. Despite the COVID-19 restrictions and general reduction in informal physical contact with peers and instructors [3], personal interactions in the F2F context persisted during the switch to online education, since online breakout rooms were set up for each team. Consequently, TBL can still create a learning environment where the instructor can support the students and give proper feedback and instruction in a rather informal setting. Therefore, the social support in the TBL approach can led to increased closeness and social cohesion [38], since the students appreciate the social connection in the TBL approach more, due to the decrease in overall social connections. A less personal approach is adopted in the LBL setting, leading to a lower level of good teaching in the COVID-19-affected semester. Consequently, it can be concluded that active learning - in the form of TBL-is highly valued by students and is certainly possible in an online setting, on the grounds that students perceive their personal interactions with the instructor to be even more important during the challenging COVID-19 pandemic.

The positive differences between TBL and LBL regarding satisfaction $(\mathrm{H} 2 \mathrm{c})$ and performance $(\mathrm{H} 3 \mathrm{c}$ ) remain unchanged in the COVID-19-affected semester compared to the non-COVID-19-affected semester. Both the TBL and the LBL students switched to an online environment and experienced that change similarly in terms of satisfaction and performance. Given that no substantial differences in satisfaction and performance were found between both semesters, it is evident that there is no interaction. This is a hopeful result as contrary to what was expected based on the results of Ghaderizefreh and Hoover [23], the lack of social contact did not lead to less course satisfaction in either of the learning paths. The conclusion that TBL outperforms LBL in terms of satisfaction also still holds, indicating that TBL can fulfill the need for connectedness [21]. The stability of performance in both semesters also underpins the conclusion that TBL can be effectively organized in an environment in which the switch from F2F to online education is made. The impact of this transformation to online education was minimized by still allowing for peer interaction, leading to a more positive impact on students' learning attitudes [2].

It can be concluded that all three options-namely, education that is fully F2F, F2F in combination with online sessions, and solely online-all have their advantages and challenges. In the LBL setting, the barrier to asking questions in a large student group is much lower in the online setting, by means of, for example, Zoom's chat function, as in the F2F context. On the contrary, maintaining a good overview of student engagement is much harder for an instructor in a fully online environment. Students also like to come to class and meet other peers in person. For the TBL approach in a F2F setting, students are obliged to come prepared to class, since the instructor can easily keep track of all the different teams at once. In addition, cooperation among peers is easier to facilitate in a F2F setting, since peers can compare their written solutions to the exercises with each other. However, the online setting has the advantage that solutions can be shared via screen sharing. Students also save time in the online environment, since no travel time is necessary to come to 
class. In addition, when the switch to an online environment had to be made and personal interactions with peers was no longer facilitated, students heavily appreciated the personal connection of the TBL approach.

An important remark must be made about the setting of the current study. This research examines a COVID-19-affected semester in which there was a switch from F2F to online learning in the middle of the ongoing semester. This setting, where half of the classes were organized on campus and the other half online, can be compared to a blended learning environment, where online learning is combined with F2F education [39]. Therefore, the conclusions of the current study can be viewed in the context of a blended learning environment, instead of an exclusively online setting. Hence, the study contributes to the current discussion on how to shape the education of the future, in a post-COVID-19 era. According to Peñarrubia-Lozano et al. [39], blended learning and blended teaching seem to be the future of education, since a blended environment is preferred to a solely online or F2F solution. Therefore, instructors are advised, based on the conclusions of the current study, to organize a TBL approach for tutorial sessions. However, the F2F version is still preferred over the fully online setting. A solely online environment should never be the initial choice, since F2F education in combination with online sessions still offers greater possibilities for interaction. Still, this study shows that, when there is an unforeseen need to switch to a fully online environment, TBL is still the preferred solution over LBL. None of the three options is the unique way forward. Consequently, the immediate switch to an online learning environment, as induced by the COVID-19 pandemic, has offered unique insights on future, post-pandemic teaching for higher education instructors.

Moreover, this study adds value to the current line of research on the effects of cooperative learning in times of COVID-19 [40]. First, the study contributes to the higher education literature in general, since it examines the effect of the COVID-19 pandemic on good teaching, satisfaction, and student performance in relation to two different learning paths. Only a few other studies have also implemented a cooperative learning approach in an online setting (e.g., [21,41]), and, to the best of our knowledge, no other study has combined both the effect of the COVID-19 pandemic and the effect on learning paths. In addition, no other study has examined the three variables of good teaching, satisfaction, and performance together. Therefore, the research design examined in this study is unique, scrutinizing both students' learning experiences and learning outcomes.

Second, most other studies only evaluate effects on students' learning within a COVID-19 affected period (e.g., [3,16]). This study, on the contrary, compares a nonCOVID-19-affected semester with a COVID-19-affected semester; therefore, the effect of the pandemic can be isolated and investigated in more detail. A similar research design is, as far as we know, used in only a few other studies (e.g., [42]).

Third, even though there was a radical switch to online learning, both learning pathsthe team-based approach and the lecture-based approach-were still offered synchronously by the same instructor as in the F2F version. The direct impact of the COVID-19 pandemic can thus be examined in both an active learning approach and a more traditional, learningbased approach, unbiased by other variations in the educational setting. The study also responds to the call of Jackson et al. [21] to examine the effect of online TBL with a larger sample and in another higher education institution. These scholars also suggested using quantitative data to examine the efficacy of the transition with a pre-post assessment, which is the research design adopted in the current study.

The present study is characterized by two main limitations, which, in turn, create opportunities for future research. First, in the current setting, COVID-19 appeared in the middle of a semester. A few weeks of on-campus F2F tutorial classes had already been completed before the switch to an online alternative had to be made. Consequently, the students were already familiar with their chosen learning path. At the time of the switch to online methods, the students in the TBL setting already knew the peers who would comprise their group for the entire semester, they were already familiar with how they should discuss the exercises within their team, and so forth. Similarly, by this time, 
the students in the LBL setting were accustomed to their instructor's way of teaching in the large group. Therefore, it would be interesting to investigate if the results of the current setting would change if the whole semester were organized online, that is, with the students unable to meet their peers for the first time in a F2F context. A clear distinction should be made between the current setting, which is comparable to a blended learning environment, and a fully online environment. Second, two surveys were conducted during both semesters to collect data on good teaching and satisfaction. However, in the COVID-19-affected semester, the first questionnaire was given on campus and the second was administered online. One wonders if this could have led to a non-response bias, since the same types of respondents might not have participated in both surveys. In addition, both surveys were collected during class time, where attendance was not compulsory. Therefore, it could be that only highly motivated students who came to every class completed the surveys. It would be interesting to examine if the same results are obtained when all students are obliged to complete both questionnaires. Despite the fact that this was not the case in the current study, the response rate was rather high.

\section{Conclusions}

Five main takeaways can be derived from this study. First, despite the difficult period of social isolation due to COVID-19 restrictions, satisfaction with the tutorial classes did not decrease among either the TBL or LBL students. This implies that the online alternative offered was a worthy equivalent of the F2F version in times of crisis. Second, students greatly appreciated their instructors, who went the extra mile in creating a supportive and cooperative online environment. Students in the TBL setting, where close interaction with peers and instructors was possible, rated the good teaching even higher compared to non-COVID-19 times. They truly appreciated the instructor's efforts to create an online alternative with a personal atmosphere. Third, this study shows that instructors have many opportunities to connect with their students via an online platform. Even if instructors no longer had the opportunity to meet their students on campus, the students appreciated the opportunities for online interaction the instructors created. Fourth, blended learning was shown to also work for practical classes, and not just for theoretical classes. Finally, TBL still outperforms LBL in terms of good teaching, satisfaction, and performance, even if it is organized in a blended learning environment. However, we would like to emphasize that this does not imply that online classes are a worthy substitute for all F2F classes. One can only conclude that, if unforeseen circumstances require a switch from F2F to online learning, TBL is still preferred over LBL, since TBL outperforms the traditional LBL setting. We therefore encourage every instructor to offer an active learning approach for tutorial classes, in both F2F and blended learning environments.

Author Contributions: Conceptualization, E.B., P.E., and E.O.; methodology, E.B., P.E., and E.O.; software, E.B.; validation, P.E.; formal analysis, E.B.; investigation, E.B.; resources, P.E., and E.O.; data curation, E.B., P.E., and E.O.; writing—original draft preparation, E.B.; writing—review and editing, P.E., and E.O.; visualization, E.B.; supervision, P.E., and E.O.; project administration, E.B. All authors have read and agreed to the published version of the manuscript.

Funding: This research received no external funding.

Institutional Review Board Statement: Not applicable. According to the Research Code of Ethics of the authors' institution, no IRB approval is needed as informed consent was provided.

Informed Consent Statement: Informed consent was obtained from all subjects involved in the study.

Data Availability Statement: The data presented in this study are available on request from the corresponding author. The data are not publicly available due to privacy restrictions.

Acknowledgments: The authors would like to thank Jasmine De Ruyck for her help with the data import and the analyses. We also would like to thank the two anonymous reviewers for their helpful comments. 
Conflicts of Interest: The authors declare no conflict of interest.

\section{Appendix A}

Table A1. Graphical representation of the hypothesized effects.

\begin{tabular}{|c|c|c|}
\hline Variable & Hypothesized E & \\
\hline \multirow{3}{*}{ H1: good teaching } & Team-based learning & \\
\hline & Lecture-based learning & \\
\hline & $\begin{array}{l}\text { Non-COVID-19- } \\
\text { affected semester }\end{array}$ & $\begin{array}{l}\text { COVID-19- } \\
\text { affected semester }\end{array}$ \\
\hline \multirow{3}{*}{ H2: satisfaction } & Team-based learning & \\
\hline & Lecture-based learning & \\
\hline & $\begin{array}{l}\text { Non-COVID-19- } \\
\text { affected semester }\end{array}$ & $\begin{array}{l}\text { COVID-19- } \\
\text { affected semester }\end{array}$ \\
\hline \multirow{3}{*}{ H3: performance } & Team-based learning & \\
\hline & Lecture-based learning & \\
\hline & $\begin{array}{l}\text { Non-COVID-19- } \\
\text { affected semester }\end{array}$ & $\begin{array}{l}\text { COVID-19- } \\
\text { affected semester }\end{array}$ \\
\hline
\end{tabular}

\section{References}

1. Pokhrel, S.; Chhetri, R. A Literature Review on Impact of COVID-19 Pandemic on Teaching and Learning. High. Educ. Futur. 2021, 8, 133-141. [CrossRef]

2. Chu, A.; Liu, C.; So, M.; Lam, B. Factors for Sustainable Online Learning in Higher Education during the COVID-19 Pandemic. Sustainability 2021, 13, 5038. [CrossRef]

3. Holzer, J.; Lüftenegger, M.; Korlat, S.; Pelikan, E.; Salmela-Aro, K.; Spiel, C.; Schober, B. Higher Education in Times of COVID-19: University Students' Basic Need Satisfaction, Self-Regulated Learning, and Well-Being. AERA Open 2021, 7, 23328584211003164. [CrossRef]

4. Detlor, B.; Booker, L.; Serenko, A.; Julien, H. Student perceptions of information literacy instruction: The importance of active learning. Educ. Inf. 2012, 29, 147-161. [CrossRef]

5. Keyser, M.W. Active learning and cooperative learning: Understanding the difference and using both styles effectively. Res. Strat. 2000, 17, 35-44. [CrossRef]

6. Slavin, R.E. Synthesis of research on cooperative learning. Educ. Leadersh. 1991, 48, 71-82.

7. Haidet, P.; Kubitz, K.; McCormack, W.T. Analysis of the Team-Based Learning Literature: TBL Comes of Age. J. Excel. Coll. Teach. 2015, 25, 303-333.

8. Healy, M.; Doran, J.; McCutcheon, M. Cooperative learning outcomes from cumulative experiences of group work: Differences in student perceptions. Account. Educ. 2018, 27, 286-308. [CrossRef]

9. Norman, C.S.; Rose, A.M.; Lehmann, C.M. Cooperative learning: Resources from the business disciplines. J. Account. Educ. 2004, 22, 1-28. [CrossRef]

10. Clinton, B.; Kohlmeyer, I. The effects of group quizzes on performance and motivation to learn: Two experiments in cooperative learning. J. Account. Educ. 2005, 23, 96-116. [CrossRef]

11. Joia, L.; Lorenzo, M. Zoom In, Zoom Out: The Impact of the COVID-19 Pandemic in the Classroom. Sustainability 2021, 13, 2531. [CrossRef]

12. Nguyen, T.; Netto, C.L.M.; Wilkins, J.F.; Bröker, P.; Vargas, E.E.; Sealfon, C.D.; Puthipiroj, P.; Li, K.S.; Bowler, J.E.; Hinson, H.R.; et al. Insights Into Students' Experiences and Perceptions of Remote Learning Methods: From the COVID-19 Pandemic to Best Practice for the Future. Front. Educ. 2021, 6, 91. [CrossRef]

13. Siqueira, A.; Simion, B. Active Learning Environments and the Transition to Online. In Proceedings of the SIGCSE '21: The 52nd ACM Technical Symposium on Computer Science Education, Virtual, 13-20 March 2021. [CrossRef]

14. Goñi, J.; Cortázar, C.; Alvares, D.; Donoso, U.; Miranda, C. Is Teamwork Different Online Versus Face-to-Face? A Case in Engineering Education. Sustainability 2020, 12, 10444. [CrossRef]

15. Tempelaar, D. Supporting the less-adaptive student: The role of learning analytics, formative assessment and blended learning. Assess. Eval. High. Educ. 2019, 45, 579-593. [CrossRef] 
16. Gopal, R.; Singh, V.; Aggarwal, A. Impact of online classes on the satisfaction and performance of students during the pandemic period of COVID 19. Educ. Inf. Technol. 2021, 26, 6923-6947. [CrossRef]

17. Jiang, H.; Islam, A.Y.M.A.; Gu, X.; Spector, J.M. Online learning satisfaction in higher education during the COVID-19 pandemic: A regional comparison between Eastern and Western Chinese universities. Educ. Inf. Technol. 2021, 26, 6747-6769. [CrossRef] [PubMed]

18. Giesbers, B.; Rienties, B.; Tempelaar, D.; Gijselaers, W. A dynamic analysis of the interplay between asynchronous and synchronous communication in online learning: The impact of motivation. J. Comput. Assist. Learn. 2013, 30, 30-50. [CrossRef]

19. Opdecam, E.; Everaert, P. Improving Student Satisfaction in a First-Year Undergraduate Accounting Course by Team Learning. Issues Account. Educ. 2012, 27, 53-82. [CrossRef]

20. Ramsden, P. A performance indicator of teaching quality in higher education: The Course Experience Questionnaire. Stud. High. Educ. 1991, 16, 129-150. [CrossRef]

21. Jackson, L.; Otaki, F.; Powell, L.; Ghiglione, E.; Zary, N. Study of a COVID-19 induced transition from Face-to-Face to Online Team-Based Learning in Undergraduate Family Medicine. MedEdPublish 2020, 9. [CrossRef]

22. Tan, H.C. Using a structured collaborative learning approach in a case-based management accounting course. J. Account. Educ. 2019, 49, 100638. [CrossRef]

23. Ghaderizefreh, S.; Hoover, M.L. Student Satisfaction with Online Learning in a Blended Course. Int. J. Digit. Soc. 2018, 9, 1393-1398. [CrossRef]

24. Johnson, D.W.; Johnson, R.T.; Smith, K. The State of Cooperative Learning in Postsecondary and Professional Settings. Educ. Psychol. Rev. 2007, 19, 15-29. [CrossRef]

25. Andres, H. The role of active teaching, academic self-efficacy, and learning behaviors in student performance. J. Int. Educ. Bus. 2020, 13, 221-238. [CrossRef]

26. Pinxten, M.; Van Soom, C.; Peeters, C.; De Laet, T.; Langie, G. At-risk at the gate: Prediction of study success of first-year science and engineering students in an open-admission university in Flanders-any incremental validity of study strategies? Eur. J. Psychol. Educ. 2017, 34, 45-66. [CrossRef]

27. Johnson, D.W.; Johnson, R.T. Making cooperative learning work. Theory Into Pract. 1999, 38, 67-73. [CrossRef]

28. Byrne, M.; Flood, B. Assessing the Teaching Quality of Accounting Programmes: An evaluation of the Course Experience Questionnaire. Assess. Evaluation High. Educ. 2003, 28, 135-145. [CrossRef]

29. Janvrin, D.J. Detecting Spreadsheet Errors: An Education Case. Issues Account. Educ. 2008, 23, 435-454. [CrossRef]

30. Chapell, M.S.; Blanding, Z.B.; Silverstein, M.E.; Takahashi, M.; Newman, B.; Gubi, A.; McCann, N. Test Anxiety and Academic Performance in Undergraduate and Graduate Students. J. Educ. Psychol. 2005, 97, 268-274. [CrossRef]

31. Everaert, P.; Opdecam, E.; Maussen, S. The relationship between motivation, learning approaches, academic performance and time spent. Account. Educ. 2017, 26, 78-107. [CrossRef]

32. Alam, M.; Ahmad, N.; Naveed, Q.; Patel, A.; Abohashrh, M.; Khaleel, M. E-Learning Services to Achieve Sustainable Learning and Academic Performance: An Empirical Study. Sustainability 2021, 13, 2653. [CrossRef]

33. Lauret, D.; Bayram-Jacobs, D. COVID-19 Lockdown Education: The Importance of Structure in a Suddenly Changed Learning Environment. Educ. Sci. 2021, 11, 221. [CrossRef]

34. Scull, J.; Phillips, M.; Sharma, U.; Garnier, K. Innovations in teacher education at the time of COVID19: An Australian perspective. J. Educ. Teach. 2020, 46, 497-506. [CrossRef]

35. Loton, D.; Parker, P.; Stein, C.; Gauci, S. Remote Learning during COVID-19: Student Satisfaction and Performance. 2020. Available online: https:/ / doi.org/10.35542/OSF.IO/N2YBD (accessed on 30 October 2021).

36. Kronenfeld, J.P.; Ryon, E.L.; Kronenfeld, D.S.; Hui, V.W.; Rodgers, S.E.; Thorson, C.M.; Sands, L.R. Medical Student Education During COVID-19: Electronic Education Does Not Decrease Examination Scores. Am. Surg. 2020. [CrossRef]

37. El Said, G.R. How Did the COVID-19 Pandemic Affect Higher Education Learning Experience? An Empirical Investigation of Learners' Academic Performance at a University in a Developing Country. Adv. Hum.-Comput. Interact. 2021, 2021, 6649524. [CrossRef]

38. Tull, M.T.; Edmonds, K.; Scamaldo, K.M.; Richmond, J.R.; Rose, J.P.; Gratz, K.L. Psychological Outcomes Associated with Stay-at-Home Orders and the Perceived Impact of COVID-19 on Daily Life. Psychiatry Res. 2020, 289, 113098. [CrossRef] [PubMed]

39. Peñarrubia-Lozano, C.; Segura-Berges, M.; Lizalde-Gil, M.; Bustamante, J. A Qualitative Analysis of Implementing E-Learning during the COVID-19 Lockdown. Sustainability 2021, 13, 3317. [CrossRef]

40. Corell-Almuzara, A.; López-Belmonte, J.; Marín-Marín, J.-A.; Moreno-Guerrero, A.-J. COVID-19 in the Field of Education: State of the Art. Sustainability 2021, 13, 5452. [CrossRef]

41. Domínguez-Lloria, S.; Fernández-Aguayo, S.; Marín-Marín, J.-A.; Alvariñas-Villaverde, M. Effectiveness of a Collaborative Platform for the Mastery of Competencies in the Distance Learning Modality during COVID-19. Sustainability 2021, $13,5854$. [CrossRef]

42. Iglesias-Pradas, S.; Hernández-García, Á.; Chaparro-Peláez, J.; Prieto, J.L. Emergency remote teaching and students' academic performance in higher education during the COVID-19 pandemic: A case study. Comput. Hum. Behav. 2021, $119,106713$. [CrossRef] 